\title{
Pre-Eclampsia-Associated Reduction in Placental Growth Factor Impaired Beta Cell Proliferation Through PI3k Signalling
}

\author{
Jun Li Huanchun Ying Guiyang Cai Quan Guo Lizhu Chen \\ Department of Gynecology and Obstetrics, Shengjing Hospital Affiliated to China Medical University, \\ Shenyang, China
}

\section{Key Words}

Preeclampsia - Placental growth factor - Beta cell proliferation •MS1, PI3k signalling • Gestational diabetes mellitus

\begin{abstract}
:
Background/Aim: Reduction in serum placental growth factor (PLGF) frequently co-occurs with preeclampsia (PE) and gestational diabetes mellitus (GDM). Recently, we reported that impairment in gestational beta-cell mass growth may result from PE-associated reduction in PLGF and lead to development of GDM. Here, we studied the underlying mechanisms. Methods: We co-cultured primary mouse beta cells with mouse islet endothelial cells (MS1), with or without PLGF. We also cultured beta cells in conditioned media from PLGF-treated MS1. Specific signal-pathway inhibitors were applied to cultured beta cells in conditioned media from PLGF-treated MS1. We analysed beta-cell proliferation by BrdU incorporation. We analysed changes in cell number by a MTT assay. We analysed protein levels of cellcycle regulators in beta cells by Western blot. Results: PLGF itself failed to induce beta-cell proliferation, but significantly augmented proliferation of beta cells co-cultured with MS1, which resulted in significant increases in cell number. Conditioned media from the PLGFtreated MS1 cells similarly induced beta-cell proliferation, which was abolished by inhibition of PI3k/Akt signalling, but not by inhibition of either ERK/MAPK or JNK signalling. The induction of beta-cell proliferation by PLGF-treated MS1 cells appeared to involve decreases in cell-cycle inhibitors p21 and p27, and increases in cell-cycle activators CDK4 and CyclinD1. Conclusion: Gestational PLGF may target islet endothelial cells to release growth factors that activate PI3k/ Akt signalling in beta cells to increase their proliferation. PE-associated reduction in PLGF impairs these processes to result in GDM.
\end{abstract}

Copyright $(2015$ S. Karger AG, Basel

Jun Li

KARGER 125
Department of Gynecology and Obstetrics, Shengjing Hospital Affiliated to China Medical University, 36 Sanhao Street, Shenyang 110004, (China)

Tel. +86249661543416, Fax +86249661543416. E-Mail jun_li14@163.com 


\section{Introduction}

During gestation, metabolic needs significantly increases. Failure of meeting these requirements may result in different complications, among which preeclampsia (PE) and gestational diabetes mellitus (GDM) are two most common ones, in which they affect more than 10\% pregnancies worldwide [1-5]. Indeed, PE and GDM have been shown to affect the function of both maternal and fatal endothelium, leading to multi-organ dysfunction and increased risk of future development of cardiovascular disease [1-5]. Many risk factors such as obesity, elevated blood pressure, dyslipidaemia, insulin resistance and hyperglycemia predispose both PE and GDM [1-5]. Moreover, PE and GDM co-occur in many patients [1-5]. However, a molecular relationship between development of PE and GDM is much unknown, until recently we reported that impairment in gestational beta-cell mass growth may result from PE-associated reduction in placental growth factor (PLGF) and lead to development of GDM [6].

PLGF is a member of the vascular endothelial growth factor (VEGF) family, which play an essential role in vasculogenesis and angiogenesis [7]. Prominent PLGF expression is largely restricted to the placenta under normal physiologic conditions [8], whereas PLGF has been recently shown to coordinate pathological angiogenesis $[9,10]$. Previous studies have shown that maternal serum PLGF levels and amniotic fluid PLGF levels are similarly low in early gestation but increase dramatically afterwards, peaking at approximately 26 to 30 weeks of gestation before subsequent decreases $[11,12]$. Thus, PLGF may enter both fatal and maternal circulations to influence vessel dynamics in both. Decreases in PLGF levels hallmark PE, characterized with poor placental vascularization [11,12].

Recently, we reported that impairment in gestational beta-cell mass growth may result from PE-associated PLGF reduction, which may explain the pathogenesis of GDM [6]. Since the PLGF has a unique receptor, VEGF receptor 1 (VEGFR1) or Flt-1, which exclusively expresses in the islet endothelial cells with the islets, but not in beta cells [13-17], we hypothesize that gestational PLGF may target islet endothelia, which release growth factors to the nearby beta cells to increase their proliferation.

In order to prove this hypothesis, we co-cultured primary mouse beta cells with mouse islet endothelial cells (MS1), with or without PLGF. We also cultured beta cells in conditioned media from PLGF-treated MS1. Specific signal-pathway inhibitors were applied to cultured beta cells in conditioned media from PLGF-treated MS1. We analysed beta-cell proliferation by BrdU incorporation. We analysed changes in cell number by a MTT assay. We analysed protein levels of cell-cycle regulators in beta cells by Western blot. We found that PLGF itself failed to induce beta-cell proliferation, but significantly augmented proliferation of beta cells co-cultured with MS1, which resulted in significant increases in cell number. Conditioned media from the PLGF-treated MS1 cells similarly induced beta-cell proliferation, which was abolished by inhibition of PI3k/Akt signalling, but not by inhibition of either ERK/ MAPK or JNK signalling. The induction of beta-cell proliferation by PLGF-treated MS1 cells appeared to involve decreases in cell-cycle inhibitors p21 and p27, and increases in cellcycle activators CDK4 and CyclinD1. Thus, our hypothesis is confirmed, which suggests that gestational PLGF may target islet endothelia to release growth factors that activate PI3k/ Akt signalling in beta cells to increase their proliferation. PE-associated reduction in PLGF impairs these processes to result in GDM.

\section{Materials and Methods}

Animals

MIP-GFP mice were purchased from Jackson Labs (Bar Harbor, ME, USA). This strain has been described before [18]. All mouse experiments were approved by and performed according to the guidelines of the IACUC of Shengjing Hospital Affiliated to China Medical University. Only 12-week-old female MIP-GFP mice were used for isolation of beta cells. The mice were kept in specific pathogen free (SPF) conditions.

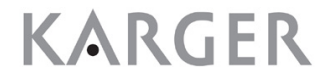




\section{Cell culture}

MS1 was purchased from American Type Culture Collection (ATCC, Rockville, MD, USA), and is a pancreatic islet endothelial cell line by transducing primary islet endothelial cells with a temperature sensitive SV40 large T antigen construct [19]. MS1 cells were cultured in Dulbecco's modified Eagle's medium (DMEM) supplemented with 10\% fetal bovine serum (Invitrogen, Carlsbad, CA, USA). Recombinant PLGF, PD168393 [20], LY294002 [21] and SP600125 [22] were all purchased from Sigma-Aldrich (St. Louis, MO, USA). The beta cells were cultured in the same culture media as MS1.

\section{Isolation of mouse beta cells}

The MIP-GFP mouse pancreas was first perfused with $0.125 \mathrm{mg} / \mathrm{ml}$ LiberaseTL (Roche, Nutley, NJ, USA) from the common bile duct, as has been described in published protocol [23, 24], then was incubated in $0.125 \mathrm{mg} / \mathrm{ml}$ LiberaseTL in a $37^{\circ} \mathrm{C}$ shaker at $200 \mathrm{rpm}$ for 45 minutes. Histopaque1077 and Histopaque1119 (Sigma-Aldrich) were mixed at a ratio of 9:33 (vol:vol) to generate Histopaque1110. Combined centrifugation in Histopaque1100 and hand-pickings were then performed to purify islets. Purified islets were further dissociated into signal cells and beta cells were purified by flow cytometry based on GFP, as has been described in published protocol [25].

\section{Transwell co-culture system}

Purified beta cells were cultured alone, or with conditioned media from PLGF-treated MS1 cells with/without inhibitors, or co-cultured in a transwell with MS1 (at a ratio of 1:1), with or without PLGF. Two days after co-culture, beta cells were analysed for proliferation by a 2-hour BrdU incorporation, or cell number in a MTT assay.

\section{MTT assay}

For assay of cell number, the beta cells $\left(10^{4}\right)$ in 24-well-plate were subjected to a Cell Proliferation Kit (MTT, Roche, Nutley, NJ, USA) after treatments in the co-culture system, according to the manufacturer's instruction.

\section{Immunocytochemistry}

Cultured mouse beta cells were fixed with $4 \%$ paraformaldehyde for 4 hours, and then used for immunocytochemistry. Double-immunostaining for GFP and BrdU was performed. Primary antibodies are guinea pig polyclonal anti-GFP and rat polyclonal anti-BrdU (Abcam, Cambridge, MA, USA). Antigen retrieval by incubation of the slides with $1 \mathrm{~mol} / \mathrm{l} \mathrm{HCl}$ at room temperature for 45 minutes was performed for BrdU staining. Secondary antibodies were Cy3- and Cy2conjugated antibodies for corresponding species (Jackson ImmunoResearch Labs, West Grove, PA, USA). DAPI (Sigma-Aldrich) is used to stain nuclei.

\section{Quantification of beta-cell proliferation}

Each experimental condition contains 5 repeats. GFP staining (in MIP-GFP mice) was used to identify beta cells. The quantification of BrdU+ beta cells in all beta cells was based on 1000 cells in each sample.

\section{Western blot}

The cells were lysed in RIPAlysis buffer (1\% NP40, 0.1\% SDS, $100 \mu \mathrm{g} / \mathrm{ml}$ phenylmethylsulfonyl fluoride, $0.5 \%$ sodium deoxycholate, in PBS) on ice. The supernatants were collected after centrifugation at $12000 \times \mathrm{g}$ at $4^{\circ} \mathrm{C}$ for $20 \mathrm{~min}$. Protein concentration was determined using a BCA protein assay kit (Bio-rad, China), and whole lysates were mixed with $4 \times$ SDS loading buffer $(125$ $\mathrm{mmol} / \mathrm{l}$ Tris- $\mathrm{HCl}, 4 \% \mathrm{SDS}, 20 \%$ glycerol, $100 \mathrm{mmol} / \mathrm{l} \mathrm{DTT}$, and $0.2 \%$ bromophenol blue) at a ratio of 1:3. Samples were heated at $100^{\circ} \mathrm{C}$ for $5 \mathrm{~min}$ and were separated on SDS-polyacrylamide gels. The separated proteins were then transferred to a PVDF membrane. The membrane blots were first probed with a primary antibody. After incubation with horseradish peroxidase-conjugated second antibody, autoradiograms were prepared using the enhanced chemiluminescent system 
to visualize the protein antigen. The signals were recorded using X-ray film. Primary antibodies for Western Blot are rabbit p21, p27, CDK4, CyclinD1 and $\alpha$-tubulin (all purchased from Cell Signaling, San Jose, CA, USA). Secondary antibody is HRP-conjugated anti-rabbit (Jackson ImmunoResearch Labs). Images shown in the figure were representative from 5 individuals.

\section{Statistics}

All values are depicted as mean \pm standard deviation from at least 5 individuals and are considered significant if $\mathrm{p}<0.05$. All data were statistically analysed using one-way ANOVA with a Bonferoni correction, followed by Fisher's exact test for comparison of two groups. The figures were generated in Prism 6.0 (GraphPad Software Inc, USA).

\section{Results}

PLGF induces beta-cell proliferation through islet endothelial cells

Recently, we reported that impairment in gestational beta-cell mass growth may result from PE-associated PLGF reduction, which may explain the pathogenesis of GDM [6]. Since the PLGF has a unique receptor, VEGFR1 or Flt-1, which exclusively expresses in the endothelial cells but not in beta cells in the islets (Fig. 1A) [13-17], we hypothesize that gestational PLGF may target islet endothelial cells, which release growth factors to the nearby beta cells to increase their proliferation.

To prove it, we co-cultured primary mouse beta cells (isolated from MIP-GFP mice) with mouse islet endothelial cells, MS1, with or without PLGF, and examined the effects on beta-

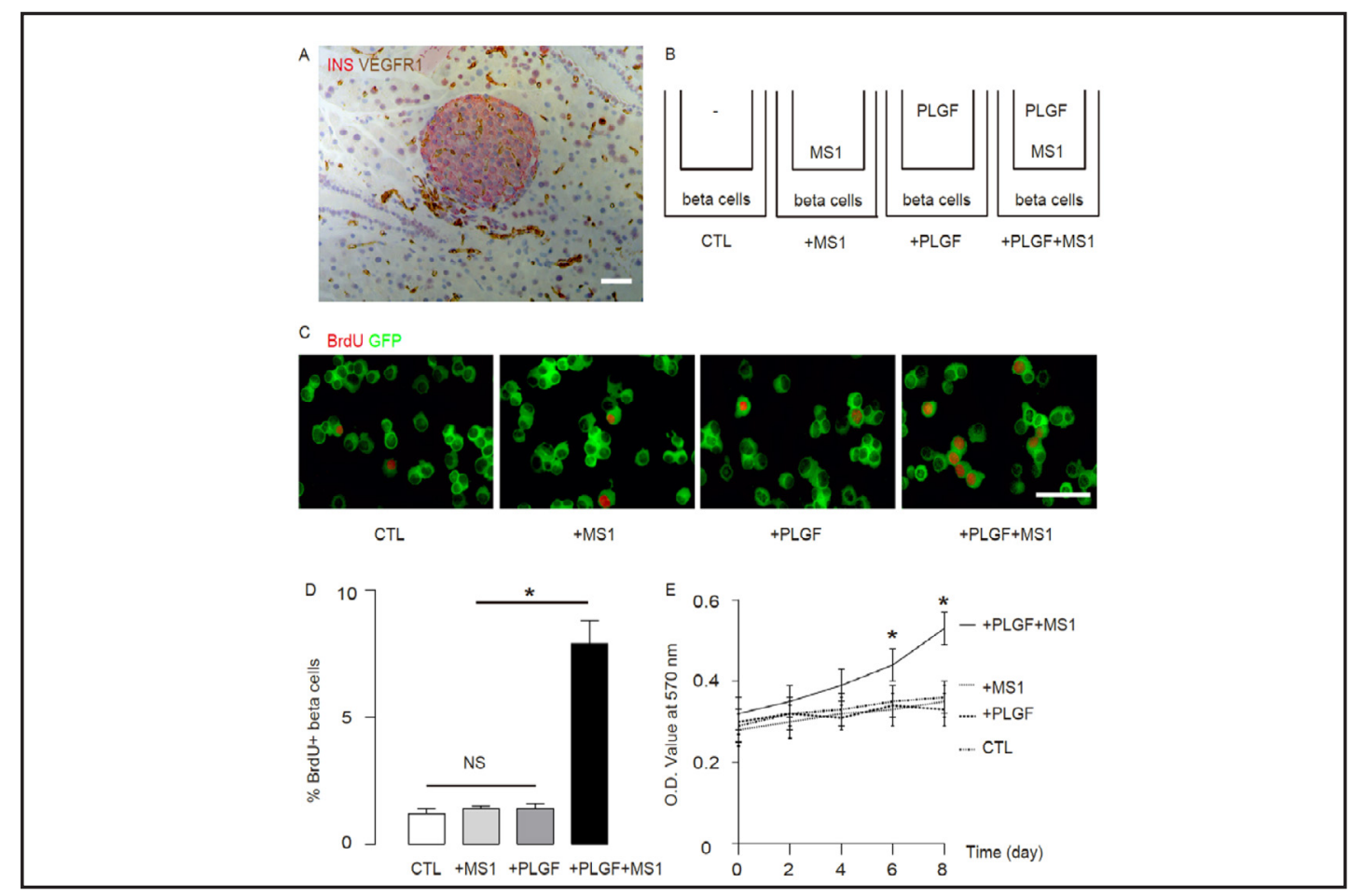

Fig. 1. PLGF induces beta-cell proliferation through islet endothelial cells. (A) An immunostaining image showing expression of VEGFR1 (in pink; fast red) and insulin (in brown; DBA) in the pancreas. (B) We cocultured primary mouse beta cells (from MIP-GFP mice) with mouse islet endothelial cells MS1 (1:1 ratio to beta cells), with or without 10ng/ml PLGF, and examined the effects on beta-cell proliferation by 24 hour's BrdU incorporation. (C-D) Beta-cell proliferation was analysed by BrdU incorporation, shown by representative images (C) and quantification (D). (E) Cell number was examined in a MTT assay. Data were shown as mean \pm SD and statistically analysed using one-way ANOVA with a Bonferoni correction. ${ }^{*} \mathrm{p}<0.05$. $\mathrm{n}=5$. Scale bars are $30 \mu \mathrm{m}$. 
A

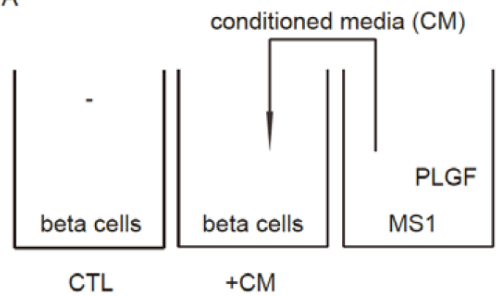

C

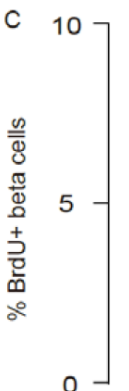

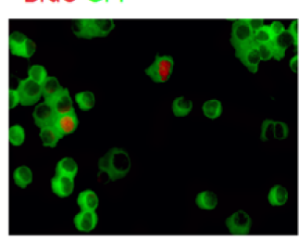

CTL

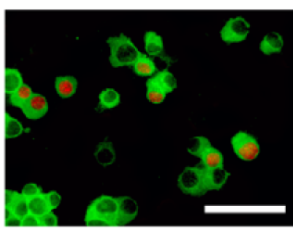

$+\mathrm{CM}$

$D$

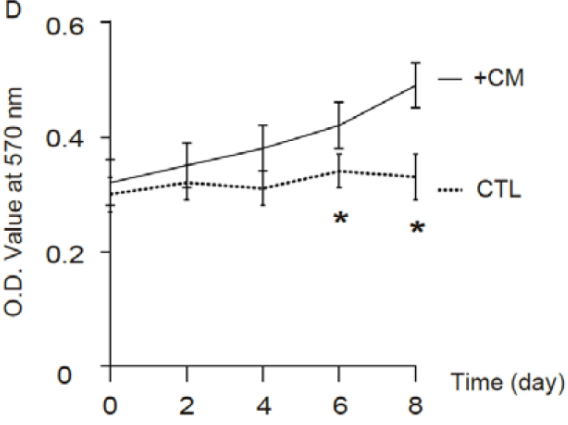

Fig. 2. PLGF-induced releases of growth factors from endothelial cells to augment beta-cell proliferation. (A) In order to figure out whether PLGF-activated endothelial cells may induce beta-cell proliferation in a paracrine-manner, we cultured beta cells in conditioned media from PLGF-treated MS1. (B-C) Beta-cell proliferation was analysed by BrdU incorporation, shown by representative images (B) and quantification (C). (D) Cell number was examined in a MTT assay. Data were shown as mean \pm SD and statistically analysed using one-way ANOVA with a Bonferoni correction. * ${ }^{*}<0.05 . n=5$. Scale bars are $30 \mu \mathrm{m}$.

cell proliferation by 24 hour's BrdU incorporation (Fig. 1B). We found that PLGF (10ng/ml) itself, or co-culture alone with MS1 cells (1:1 ratio to beta cells) failed to induce beta-cell proliferation, whereas PLGF significantly augmented proliferation of beta cells co-cultured with MS1 (Fig. 1C-D), resulting in significant increases in beta-cell number in a MTT assay (Fig. 1E). These data support our hypothesis that PLGF may target islet endothelial cells, and then the activated endothelial cells promote beta-cell proliferation.

PLGF-induced releases of growth factors from endothelial cells to augment beta-cell proliferation

In order to figure out whether PLGF-activated endothelial cells may induce beta-cell proliferation in a paracrine-manner, we cultured beta cells in conditioned media from PLGFtreated MS1 (Fig. 2A). We found that these conditioned media significantly increased betacell proliferation (Fig. 2B-C), resulting in significant increases in beta-cell number in a MTT assay (Fig. 2D). These data suggest that PLGF may target and activate islet endothelial cells, which release growth factors to promote beta-cell proliferation in a paracrine manner.

\section{Conditioned media from the PLGF-treated MS1 cells induce beta-cell proliferation through} PI3k/Akt signalling

In order to understand the molecular mechanisms underlying these PLGF-initiated beta-cell proliferation, we applied specific signal-pathway inhibitors to cultured beta cells in conditioned media from PLGF-treated MS1 (Fig. 3A).

Since PI3k/Akt, ERK/MAPK and JNK signalling pathways have been previously shown to be involved in beta-cell proliferation in different models, we thus used either $20 \mu \mathrm{mol} / \mathrm{l}$ LY294002 (LY), a specific inhibitor to Akt, to inhibit PI3k/Akt signalling cascades in cultured beta cells treated with conditioned media from PLGF-treated MS1, or $10 \mu \mathrm{mol} / \mathrm{l}$ PD98059 (PD), a specific inhibitor to ERK1/2, to inhibit ERK/MAPK signalling cascades in cultured 
A

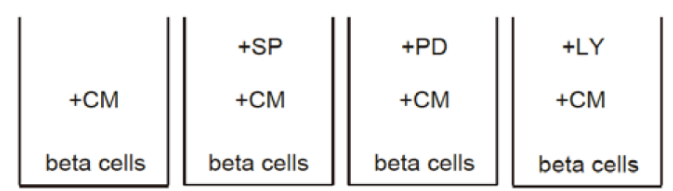

B BrdU GFP

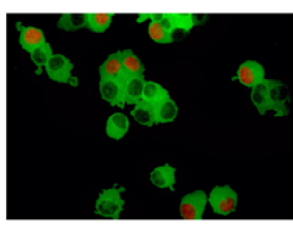

$+\mathrm{CM}$

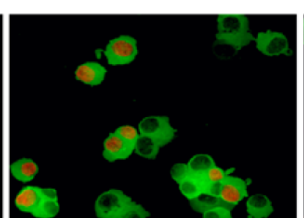

$+\mathrm{CM}+\mathrm{SP}$

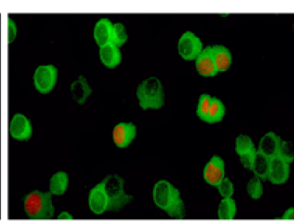

$+\mathrm{CM}+\mathrm{PD}$
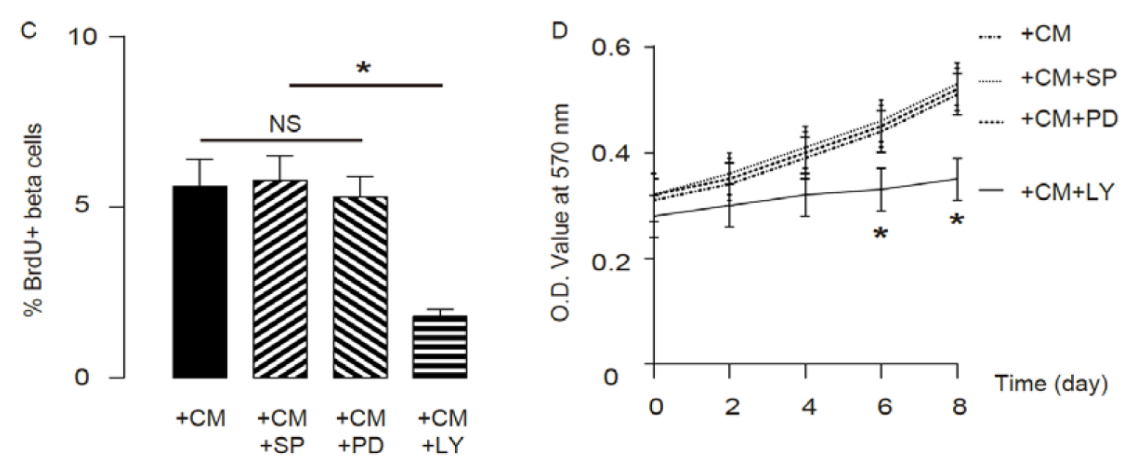

Fig. 3. Conditioned media from the PLGF-treated MS1 cells induce beta-cell proliferation through PI3k/ Akt signalling. (A) In order to understand the molecular mechanisms underlying these PLGF-initiated betacell proliferation, we applied specific signal-pathway inhibitors to cultured beta cells in conditioned media from PLGF-treated MS1. We used either 20 $\mathrm{mol} / \mathrm{l}$ LY294002 (LY), a specific inhibitor to Akt, to inhibit PI3k/ Akt signalling cascades in cultured beta cells treated with conditioned media from PLGF-treated MS1, or $10 \mu \mathrm{mol} / \mathrm{l}$ PD98059 (PD), a specific inhibitor to ERK1/2, to inhibit ERK/MAPK signalling cascades in cul-

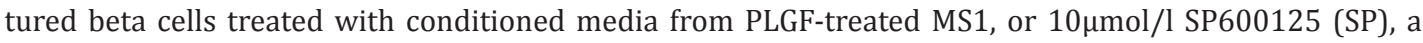
specific inhibitor to JNK, to inhibit JNK signalling cascades in cultured beta cells treated with conditioned media from PLGF-treated MS1. (B-C) Beta-cell proliferation was analysed by BrdU incorporation, shown by representative images (B) and quantification (C). (D) Cell number was examined in a MTT assay. Data were shown as mean \pm SD and statistically analysed using one-way ANOVA with a Bonferoni correction. ${ }^{*} \mathrm{p}<0.05$. $\mathrm{n}=5$. Scale bars are $30 \mu \mathrm{m}$.

beta cells treated with conditioned media from PLGF-treated MS1, or $10 \mu \mathrm{mol} / \mathrm{l}$ SP600125 (SP), a specific inhibitor to JNK, to inhibit JNK signalling cascades in cultured beta cells treated with conditioned media from PLGF-treated MS1 (Fig. 3A).

We found that only application of LY significantly abolished the increases in beta-cell proliferation by conditioned media from PLGF-treated MS1 (Fig. 3B-C), and subsequently the increases in cell number (Fig. 3D). These data suggest that gestational PLGF may target islet endothelial cells to release growth factors that activate PI3k/Akt signalling in beta cells to increase their proliferation.

Activation of PI3k/Akt signalling in beta cells may increase beta-cell proliferation through modulation of cell-cycle regulators p21, p27, CDK4 and CyclinD1

We isolated proteins from treated beta cells, and analysed cell-cycle regulators by Western blot. We found that beta-cell proliferation by conditioned media from PLGF-treated MS1 decreased cellular levels of cell-cycle inhibitor p21 and p27, and increased cellular levels of cell-cycle activator CDK4 and CyclinD1 (Fig. 4). Moreover, these modulations of cell- 
Fig. 4. Activation of PI3k/Akt signalling in beta cells may increase beta-cell proliferation through modulation of cell-cycle regulators p21, p27, CDK4 and CyclinD1. We isolated proteins from treated beta cells, and analysed cell-cycle regulators p21, p27, CDK4 and CyclinD1 by Western blot. We found that beta-cell proliferation by conditioned media from PLGF-treated MS1 decreased cellular levels of cellcycle inhibitor p21 and p27, and increased cellular levels of cell-cycle activator CDK4 and CyclinD1. Bcl2 was not affected. Moreover, these modulations of cell-cycle regulators were abolished by inhibition of PI3k/Akt signalling, but not by inhibition of either ERK/MAPK or JNK signalling.

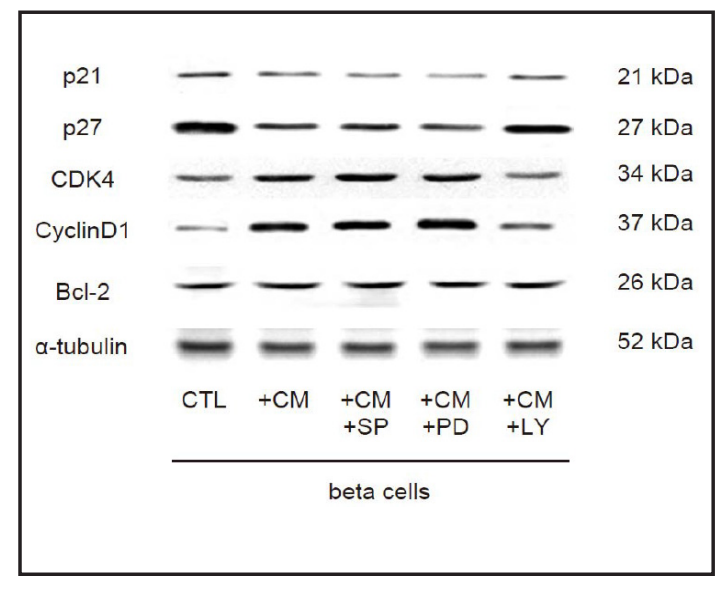

Fig. 5. Schematic of the model. Model of contribution of reduced gestational PLGF to PE and GDM.

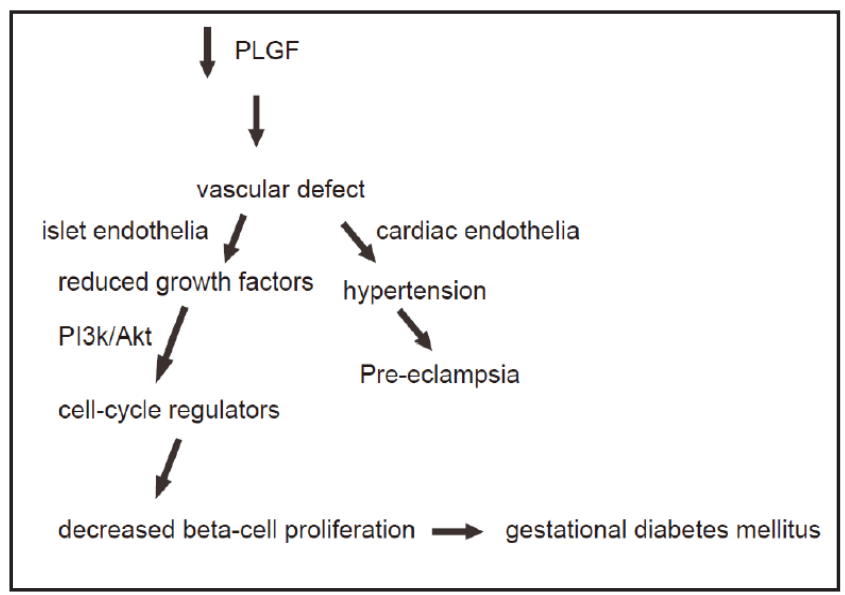

cycle regulators were abolished by inhibition of PI3k/Akt signalling, but not by inhibition of either ERK/MAPK or JNK signalling (Fig. 4). Together, these data suggest that activation of PI3k/Akt signalling in beta cells may increase beta-cell proliferation through modulation of cell-cycle regulators p21, p27, CDK4 and CyclinD1. Together with our previous findings [6], the model of contribution of reduced gestational PLGF to PE and GDM has been illustrated (Fig. 5).

\section{Discussion}

PE and GDM are two common obstetric complications and appear to be the leading causes of maternal and fatal mortality. Although these two complications have a high frequency to co-occur in many patients, their relationships in terms of the pathogenesis have not been fully elucidated.

In our previous study, we confirmed reduced serum PLGF levels in pregnant women with PE. We have also detected a strong correlation between serum PLGF levels and presence of GDM. To study the possible causal link and underlying mechanism, we have used a wellestablished L-NAME mouse model for human PE, which induces all PE-like features, like hypertension, proteinuria, renal damage and fatal growth retardation. Then we analysed whether the growth of beta-cell mass during pregnancy may be affected by L-NAME injection in this PE model. Our result show a significant impairment in beta-cell mass growth after L-NAME treatment. We found a substantial increase in beta-cell proliferation in pregnant mice, which significantly decreased by L-NAME injection. In a gain-of-function experiment, exogenous PLGF in a subcutaneous implant pump corrected the reduction in beta-cell mass 
and PE-associated features by L-NAME injection. Since we did not find alteration in islet vessel density by modulation of PLGF levels, the effect of PLGF on beta-cell growth may not require the growth of islet capillary $[26,27]$.

Based on these findings, we hypothesize that PLGF may activate specific signal transduction in islet endothelial cells after it binds to VEGFR1 in these cells, which triggers the production and secretion of trophic factors to promote proliferation of the adjacent beta cells in a paracrine manner. In this study, we tried to prove this hypothesis.

In the co-culture system, neither PLGF itself, nor co-culture alone with MS1 cells, but PLGF plus MS1 induced beta-cell proliferation. The first two conditions, together with untreated beta cells were used as controls to demonstrate that PLGF indeed targets endothelial cells, rather than beta cells, and the activated endothelial cells further induce beta-cell proliferation. Since beta cells and MS1 were co-cultured in a transwell, cell-contact is not required for beta-cell proliferation, which suggests that PLGF may target and activate islet endothelial cells, which release growth factors to promote beta-cell proliferation in a paracrine manner. These data were further supported by the conditioned media from PLGFtreated MS1 similarly induced beta-cell proliferation.

Next we added specific signal-pathway inhibitors to cultured beta cells in conditioned media from PLGF-treated MS1. Only application of LY significantly abolished the increases in beta-cell proliferation by conditioned media from PLGF-treated MS1, suggesting that gestational PLGF may target islet endothelial cells to release growth factors that activate PI3k/ Akt signalling in beta cells to increase their proliferation. We isolated proteins from treated beta cells, and analysed cell-cycle regulators by Western blot, and found that activation of PI3k/Akt signalling in beta cells may increase beta-cell proliferation through modulation of cell-cycle regulators p21, p27, CDK4 and CyclinD1. We also examined some other cellcycle-associated proteins. CyclinE, cyclinB, Bak, Bid, and caspase 9 were not expressed in beta cells, while Bcl-2 was not significantly changed. Together, these data are consistent with the previous findings in PI3k/Akt pathway, since Akt can phosphorylate Fox01 to release Fox01 from p21 and p27 promoter, and Akt can activate mTor to directly activate CDK4 and CyclinD1 $[28,29]$. Together with our previous findings [6], our studies suggest a model in that PLGFs play a key role in gestation. Reduction of PLGF may induce vascular defects that affect cardiac endothelial cells to induce hypertension and other PE-like symptoms. Reduction of PLGF may also induce vascular defects that affect islet endothelial cells that are needed to release growth factors to augment beta-cell proliferation. Future experiments may address identification of these beta-cell trophic factors released by PLGF-activated islet endothelial cells.

\section{Disclosure Statement}

None disclosed.

\section{Acknowledgement}

This work is financially supported by National Natural Science Foundation of China (NSFC) no: 81372486.

\section{Reference}

1 Maynard S, Epstein FH, Karumanchi SA: Preeclampsia and angiogenic imbalance. Annu Rev Med 2008;59:61-78.

-2 Rao R, Sen S, Han B, Ramadoss S, Chaudhuri G: Gestational diabetes, preeclampsia and cytokine release: Similarities and differences in endothelial cell function. Adv Exp Med Biol 2014;814:69-75. 


\section{Cellular Physiology Cell Physiol Biochem 2015;36:34-43 \begin{tabular}{ll|l} 
and Biochemistry Publisned oninne: April 27, 2015 & $\begin{array}{l}\text { (c) 2015 S. Karger AG, Basel } \\
\text { www.karger.com/cpb }\end{array}$ \\
\hline
\end{tabular}}

Li et al.: PLGF Impairs Beta-Cell Proliferation Through PI3k

-3 Schneider S, Freerksen N, Rohrig S, Hoeft B, Maul H: Gestational diabetes and preeclampsia--similar risk factor profiles? Early Hum Dev 2012;88:179-184.

4 Dempsey JC, Butler CL, Williams MA: No need for a pregnant pause: Physical activity may reduce the occurrence of gestational diabetes mellitus and preeclampsia. Exerc Sport Sci Rev 2005;33:141-149.

5 Wen SW, Xie RH, Tan H, Walker MC, Smith GN, Retnakaran R: Preeclampsia and gestational diabetes mellitus: Pre-conception origins? Med Hypotheses 2012;79:120-125.

-6 Li J, Ying H, Cai G, Guo Q, Chen L: Impaired proliferation of pancreatic beta cells, by reduced placental growth factor in pre-eclampsia, as a cause for gestational diabetes mellitus. Cell Prolif 2015;48:166-174. Ferrara N: Vascular endothelial growth factor. Arterioscler Thromb Vasc Biol 2009;29:789-791.

Maglione D, Guerriero V, Viglietto G, Delli-Bovi P, Persico MG: Isolation of a human placenta cdna coding for a protein related to the vascular permeability factor. Proc Natl Acad Sci U S A 1991;88:9267-9271.

-9 Autiero M, Waltenberger J, Communi D, Kranz A, Moons L, Lambrechts D, Kroll J, Plaisance S, De Mol M, Bono F, Kliche S, Fellbrich G, Ballmer-Hofer K, Maglione D, Mayr-Beyrle U, Dewerchin M, Dombrowski S, Stanimirovic D, Van Hummelen P, Dehio C, Hicklin DJ, Persico G, Herbert JM, Shibuya M, Collen D, Conway EM, Carmeliet P: Role of plgf in the intra- and intermolecular cross talk between the vegf receptors flt1 and flk1. Nat Med 2003;9:936-943.

10 Fischer C, Jonckx B, Mazzone M, Zacchigna S, Loges S, Pattarini L, Chorianopoulos E, Liesenborghs L, Koch M, De Mol M, Autiero M, Wyns S, Plaisance S, Moons L, van Rooijen N, Giacca M, Stassen JM, Dewerchin M, Collen D, Carmeliet P: Anti-plgf inhibits growth of vegf(r)-inhibitor-resistant tumors without affecting healthy vessels. Cell 2007;131:463-475.

11 Torry DS, Wang HS, Wang TH, Caudle MR, Torry RJ: Preeclampsia is associated with reduced serum levels of placenta growth factor. Am J Obstet Gynecol 1998;179:1539-1544.

12 Tidwell SC, Ho HN, Chiu WH, Torry RJ, Torry DS: Low maternal serum levels of placenta growth factor as an antecedent of clinical preeclampsia. Am J Obstet Gynecol 2001;184:1267-1272.

13 Brissova M, Aamodt K, Brahmachary P, Prasad N, Hong JY, Dai C, Mellati M, Shostak A, Poffenberger G, Aramandla R, Levy SE, Powers AC: Islet microenvironment, modulated by vascular endothelial growth factor-a signaling, promotes beta cell regeneration. Cell Metab 2014;19:498-511.

14 Brissova M, Shostak A, Shiota M, Wiebe PO, Poffenberger G, Kantz J, Chen Z, Carr C, Jerome WG, Chen J, Baldwin HS, Nicholson W, Bader DM, Jetton T, Gannon M, Powers AC: Pancreatic islet production of vascular endothelial growth factor--a is essential for islet vascularization, revascularization, and function. Diabetes 2006;55:2974-2985.

15 Xiao X, Guo P, Chen Z, El-Gohary Y, Wiersch J, Gaffar I, Prasadan K, Shiota C, Gittes GK: Hypoglycemia reduces vascular endothelial growth factor a production by pancreatic beta cells as a regulator of beta cell mass. J Biol Chem 2013;288:8636-8646.

16 Xiao X, Prasadan K, Guo P, El-Gohary Y, Fischbach S, Wiersch J, Gaffar I, Shiota C, Gittes GK: Pancreatic duct cells as a source of vegf in mice. Diabetologia 2014;57:991-1000.

-17 Lammert E, Cleaver 0, Melton D: Induction of pancreatic differentiation by signals from blood vessels. Science 2001;294:564-567.

-18 Hara M, Wang X, Kawamura T, Bindokas VP, Dizon RF, Alcoser SY, Magnuson MA, Bell GI: Transgenic mice with green fluorescent protein-labeled pancreatic beta -cells. Am J Physiol Endocrinol Metab 2003;284:E177-183.

19 Arbiser JL, Moses MA, Fernandez CA, Ghiso N, Cao Y, Klauber N, Frank D, Brownlee M, Flynn E, Parangi S, Byers HR, Folkman J: Oncogenic h-ras stimulates tumor angiogenesis by two distinct pathways. Proc Natl Acad Sci U S A 1997;94:861-866.

20 Xiao X, Gaffar I, Guo P, Wiersch J, Fischbach S, Peirish L, Song Z, El-Gohary Y, Prasadan K, Shiota C, Gittes GK: M2 macrophages promote beta-cell proliferation by up-regulation of smad7. Proc Natl Acad Sci U S A 2014;111:E1211-1220.

21 Vlahos CJ, Matter WF, Hui KY, Brown RF: A specific inhibitor of phosphatidylinositol 3-kinase, 2-(4-morpholinyl)-8-phenyl-4h-1-benzopyran-4-one (ly294002). J Biol Chem 1994;269:5241-5248.

22 Bennett BL, Sasaki DT, Murray BW, O'Leary EC, Sakata ST, Xu W, Leisten JC, Motiwala A, Pierce S, Satoh Y, Bhagwat SS, Manning AM, Anderson DW: Sp600125, an anthrapyrazolone inhibitor of jun n-terminal kinase. Proc Natl Acad Sci U S A 2001;98:13681-13686.

23 Perides G, van Acker GJ, Laukkarinen JM, Steer ML: Experimental acute biliary pancreatitis induced by retrograde infusion of bile acids into the mouse pancreatic duct. Nat Protoc 2010;5:335-341. 


\section{Cellular Physiology Cell Physiol Biochem 2015;36:34-43 \begin{tabular}{l|l|}
\hline DOI: 10.1159/000374051 & O 2015 S. Karger AG, Basel
\end{tabular} \\ Li et al.: PLGF Impairs Beta-Cell Proliferation Through PI3k}

-24 Xiao X, Guo P, Prasadan K, Shiota C, Peirish L, Fischbach S, Song Z, Gaffar I, Wiersch J, El-Gohary Y, Husain SZ, Gittes GK: Pancreatic cell tracing, lineage tagging and targeted genetic manipulations in multiple cell types using pancreatic ductal infusion of adeno-associated viral vectors and/or cell-tagging dyes. Nat Protoc 2014;9:2719-2724.

-25 Xiao X, Chen Z, Shiota C, Prasadan K, Guo P, El-Gohary Y, Paredes J, Welsh C, Wiersch J, Gittes GK: No evidence for beta cell neogenesis in murine adult pancreas. J Clin Invest 2013;123:2207-2217.

-26 Lammert E, Gu G, McLaughlin M, Brown D, Brekken R, Murtaugh LC, Gerber HP, Ferrara N, Melton DA: Role of vegf-a in vascularization of pancreatic islets. Curr Biol 2003;13:1070-1074.

27 Nikolova G, Jabs N, Konstantinova I, Domogatskaya A, Tryggvason K, Sorokin L, Fassler R, Gu G, Gerber HP, Ferrara N, Melton DA, Lammert E: The vascular basement membrane: A niche for insulin gene expression and beta cell proliferation. Dev Cell 2006;10:397-405.

28 Owonikoko TK, Khuri FR: Targeting the pi3k/akt/mtor pathway: Biomarkers of success and tribulation. American Society of Clinical Oncology educational book / ASCO American Society of Clinical Oncology Meeting 2013.

-29 Polivka J Jr, Janku F: Molecular targets for cancer therapy in the pi3k/akt/mtor pathway. Pharmacol Ther 2014;142:164-175. 